\title{
Equity Option-Implied Probability of Default and Equity Recovery Rate
}

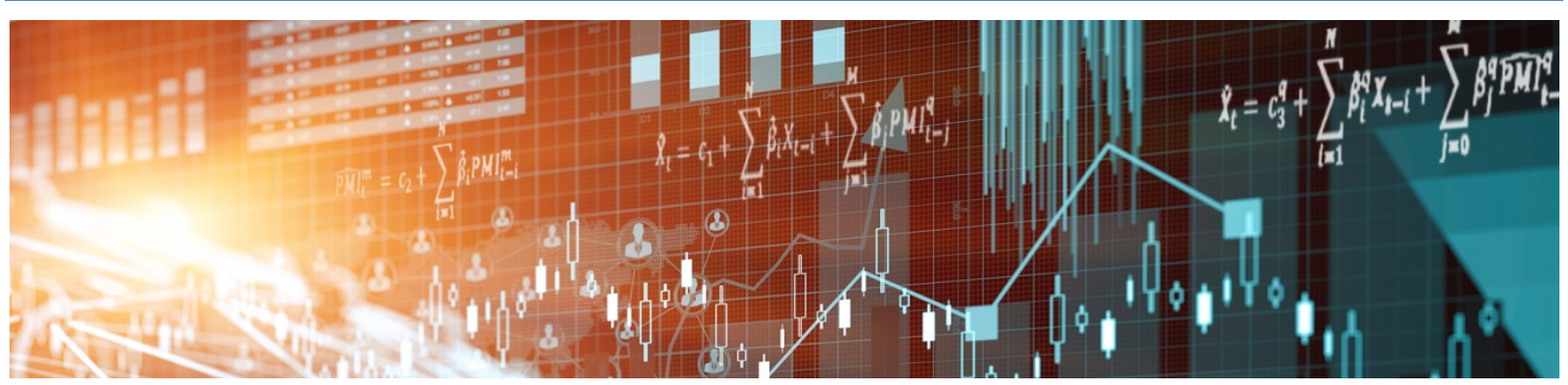

by Bo Young Chang and Greg Orosi 
Bank of Canada Staff Working Paper 2016-58

December 2016

\section{Equity Option-Implied Probability of Default and Equity Recovery Rate}

by

Bo Young Chang ${ }^{1}$ and Greg Orosi ${ }^{2}$

${ }^{1}$ Financial Markets Department

Bank of Canada

Ottawa, Ontario, Canada K1A 0G9

bchang@bankofcanada.ca

2Department of Mathematics and Statistics

American University of Sharjah

Sharjah, UAE

gorosi@aus.edu 


\section{Acknowledgements}

We thank Robert Webb (Editor), the anonymous referee, Kwangil Bae, Narayan Bulusu, Peter Christoffersen, Bruno Feunou, Jean-Sébastien Fontaine, José Da Fonseca and Jun Yang, as well as participants at the Bank of Canada Fellowship Learning Exchange, Quantitative Methods in Finance Conference, Auckland Centre for Financial Research Derivative Markets Conference, and the Annual Conference of the Asia-Pacific Association of Derivatives for helpful comments and suggestions. 


\begin{abstract}
There is a close link between prices of equity options and the default probability of a firm. We show that in the presence of positive expected equity recovery, standard methods that assume zero equity recovery at default misestimate the option-implied default probability. We introduce a simple method to detect stocks with positive expected equity recovery by examining option prices and propose a method to extract the default probability from option prices that allows for positive equity recovery. We demonstrate possible applications of our methodology with examples that include large financial institutions in the United States during the 2007-09 subprime crisis.
\end{abstract}

Bank topics: Asset pricing; Financial markets; Market structure and pricing JEL codes: G13; G33

\title{
Résumé
}

Il existe un lien étroit entre les prix des options sur actions et la probabilité de défaillance d'une entreprise. Nous montrons qu'en présence d'une valeur de recouvrement espérée positive des actions, les méthodes usuelles, qui reposent sur l'hypothèse d'un taux de recouvrement nul de la valeur des actions en cas de défaillance, estiment mal la probabilité de défaillance implicite. Nous présentons une méthode simple, fondée sur l'examen du prix des options, pour détecter les actions dont le taux de recouvrement espéré est positif. Nous proposons aussi une méthode pour extraire la probabilité de défaillance à partir des prix des options, qui postule un recouvrement positif de la valeur des actions. Nous illustrons les utilisations possibles de notre démarche en l'appliquant entre autres aux cas de grandes institutions financières aux États-Unis durant la crise des prêts hypothécaires à risque des années 2007 à 2009.

Sujets : Évaluation des actifs; Marchés financiers; Structure de marché et fixation des prix

Codes JEL : G13; G33 


\section{Non-Technical Summary}

Payoffs from a stock option depend on the future price of a stock. As a result, prices of options on a given stock contain information on the investors' predictions of how the stock will perform in the future. In particular, it is possible to gauge the investors' perception of how likely a firm is to default within a certain time horizon by observing prices of options written on the firm's stock.

Existing methodologies that attempt to link the probability of default of a firm with its stock option prices assume that when a firm defaults, the stock price goes to zero. The assumption is valid most of the time in practice, but can be violated under some situations. One such example is Chapter 11 bankruptcy. Unlike Chapter 7 bankruptcy following which a firm is simply liquidated, Chapter 11 bankruptcy allows for a reorganization of the firm in which bond holders and equity holders can renegotiate to avoid liquidation of the firm. Although Chapter 11 bankruptcies are often considered a default event, the firm's stock price under Chapter 11 does not necessarily go to zero immediately following the bankruptcy filing. This is because of the possibility of successful reorganization that often leaves positive values for equity holders. Another example is government bailout of distressed firms. In this case, a firm goes through a near-default event, but its stock price often stays above zero following the government's intervention.

This study shows that relaxing the assumption of zero stock price at default has implications for pricing options and for extracting the probability of default from option prices. We first derive new lower bounds that the prices of European call and put options must satisfy when we allow positive stock price at default. We show that violations of these new lower bounds can be used to identify firms that are likely to have positive stock price at default. Our empirical results based on six large US financial institutions during the 2007-09 subprime crisis show that the lower-bound violations were frequent for these firms. The result is consistent with the fact that bailout of these institutions by the US government was highly anticipated during the crisis.

In the last part of the paper, we examine the implication of allowing positive stock price at default for extracting the probability of default from option prices. We demonstrate that the default probabilities estimated allowing positive stock price at default are significantly different from those obtained under zero stock price assumption, and much closer to the estimates obtained from the spreads of credit default swaps of the same firm. 


\section{Introduction}

There is a large body of literature linking option pricing models with the probability of default of a firm, following the seminal work by Merton (1974). Most of the studies in this literature (e.g., Bayraktar \& Yang, 2011; Carr \& Linetsky, 2006; Carr \& Madan, 2010; Carr \& Wu, 2009; and Linetsky, 2006) assume that there is no residual asset left to pay equity investors in the event of a firm's default. That is, the stock price goes to zero when a default occurs. In most cases, the assumption of zero equity recovery at default is valid. However, in some instances, there is significant residual value to equity investors even after a firm defaults.

To file for bankruptcy, a company is supposed to be insolvent, with debts exceeding assets. Since debt holders must be paid back before shareholders, firms do not typically have residual funds to pay equity holders. However, some firms end up in Chapter 11 bankruptcy, not because they are insolvent, but because they cannot get new loans or refinance existing debt. Furthermore, for various strategic reasons, both equity holders and debt holders have incentives to induce bankruptcy well before the equity value reaches zero. ${ }^{1}$

Ignoring a positive expected equity recovery at default has important implications for pricing options and also for estimating the probability of default from observed option prices. This study makes two important contributions to the literature. First, we propose a simple method to detect stocks with positive expected equity recovery by examining prices of equity options. Second, we propose a simple closed-form equity call option pricing formula that takes positive equity recovery into account.

Our methodology is based on new static arbitrage-free lower bounds for European call and put option prices when the expected default probability and equity recovery are known. We derive these lower bounds by generalizing the results of Orosi (2014).

The second part of the paper examines possible applications of the new lower bounds. Due to data limitation, empirical studies are based on only a small number of firms that serve an illustrative purpose only. First, we use the prices of options on General Motors (GM) stock close to its bankruptcy filing in June 2009 to illustrate how the violation of the proposed lower bounds can be used to detect positive expected recovery for GM. We also apply our method to six large US financial institutions that were under tremendous stress during the financial crisis of 2007-09. We find that lower-bound violations occurred frequently for options on these stocks, indicating that the expected equity recovery rates of these stocks were often positive during the crisis. The positive equity recovery rates for these stocks are consistent with what eventually happened to these firms. Some were acquired by other institutions at very low prices (Bear Stearns and Merrill Lynch) while one was bailed out by the government (AIG). The positive expected recovery rates reflect the investors' expectations of what the

\footnotetext{
${ }^{1}$ See Leland (1994); Leland and Toft (1996); Fan and Sundaresan (2000); Broadie, Chernov, and Sundaresan (2007); Hackbarth, Hennessy, and Leland (2007); and Davydenko (2012).
} 
stocks of these firms would be worth after going through near-default events such as distressed acquisitions and government bailouts.

The new lower bounds with positive equity recovery can be also used to extend the closed-form equity option pricing formula of Orosi (2015a). The model allows us to estimate the equity recovery rate and the probability of default. We calibrate two versions of the model: the new formula that allows for positive equity recovery and the formula in Orosi (2015a) that assumes zero recovery. We then compare the probability of default estimated from the two versions of the model, with the probability of default estimated from credit default swaps (CDS) for MGM Resorts International in 2009.

We find that the probabilities of default estimated with positive recovery are comparable to the CDS-implied probabilities of default, whereas the probabilities estimated under the zero recovery assumption are significantly lower than those implied from CDS. Our example illustrates that ignoring a positive expected equity recovery at default has important implications for estimating probability of default from observed option prices. Therefore, other methods of estimating probability of default from option prices, such as Carr and Wu (2011) and Taylor et al. (2014) must be used with caution when the equity recovery is expected to be positive.

The rest of the paper is organized as follows: In Section 2, we show how the violation of lower bounds for option prices can be explained by positive equity recovery at default. Section 3 describes the data. In Section 4, we present examples of the application of the proposed methodology for detecting positive expected equity recovery from option prices. In Section 5 , we propose an interpolation-based, closed-form formula that can be used to infer the probability of default from equity options when expected recovery is positive. Section 6 concludes the paper.

\section{Violation of Lower Bounds for Options on a Defaultable Asset}

The lower bounds for European call and put prices derived in Merton (1973) (referred to hereafter as Merton's lower bounds) are based on the assumption that the underlying asset price follows a strictly positive price process, which is not the case when there is a positive probability of default. Orosi (2014) proposes improved lower bounds under the assumption that the underlying asset can default and the price of the asset at default is zero. In the case of equity options, this means a zero equity recovery at default.

$$
\begin{gathered}
P(K, T) \geq \max \left(e^{-r T} \cdot K \cdot P D, 0\right), \\
C(K, T) \geq \max \left(S_{0} e^{-d T}-e^{-r T}(1-P D) \cdot K, 0\right) .
\end{gathered}
$$

In practice, however, Orosi's lower bounds are often violated for equity options. In this section, we first present an alternative derivation of the lower bounds proposed in Orosi (2014), then show that relaxing the assumption of 
zero equity recovery can explain the presence of violations of Orosi's bounds in practice.

\subsection{Lower bounds with zero equity recovery}

Following Merton (1973), we assume: $(i)$ perfect capital markets; $(i i)$ there are no arbitrage opportunities; (iii) investors have positive marginal utility of wealth; and (iv) current and future interest rates are strictly positive. Let $C(K, T)$ and $P(K, T)$ be the current prices of European call and put options on the stock with strike $K$ and maturity $T . r$ and $d$ denote the interest rate and the continuous dividend yield, respectively.

Consider a stock that has a current price of $S_{0}$ with a positive risk-neutral default probability of $P D$ prior to some time $T$. Then, since the stock is worthless in the case of default,

$$
\begin{gathered}
P D=P\left(S_{T}=0\right), \\
P\left(S_{T}>0\right)=1-P D .
\end{gathered}
$$

Moreover, as De Marco et al. (2013) show, $P\left(S_{T}>0\right)$ can be calculated from call options using the identity of Breeden and Litzenberger (1978) and is given by

$$
P\left(S_{T}>0\right)=-\left.e^{-r T} \frac{\partial^{+} C(K, T)}{\partial K}\right|_{K=0}=-e^{-r T}\left(\lim _{\Delta K \rightarrow 0} \frac{C(\Delta K, T)-C(0, T)}{\Delta K}\right) .
$$

Then, a digital contract that pays a unit currency at time $T$ if default happens prior to time $T$ and pays zero otherwise is given by

$$
D(T)=e^{-r T} \cdot P D
$$

and can be replicated in terms of call options and cash, as follows:

$$
\begin{aligned}
D(T) & =e^{-r T} \cdot P D=e^{-r T}-e^{-r T} P\left(S_{T}>0\right)= \\
e^{-r T}+\left.\frac{\partial^{+} C(K, T)}{\partial K}\right|_{K=0} & =e^{-r T}+\lim _{\Delta K \rightarrow 0} \frac{C(\Delta K, T)-C(0, T)}{\Delta K} .
\end{aligned}
$$

Proposition 1 The lower bound of a European put option written on a defaultable asset is

$$
P(K, T) \geq e^{-r T} \cdot K \cdot P D .
$$

Proof. Assuming otherwise, one can assume that (4) does not hold and form the following zero value portfolio at time zero:

$$
\Pi=P(K, T)-K \cdot D(T)+B
$$

where $B$ represent the amounts invested in bonds. In the case of default, the value of the portfolio at the time of expiry is given by:

$$
\Pi=K-K+B e^{r T}=B e^{r T}>0
$$


because the payoff of $D(T)=1$. If the asset does not default prior to expiry and the option does not finish in the money (or $S_{T}>K$ equivalently), then the value of the portfolio at the time of expiry is given by

$$
\Pi=B e^{r T}>0
$$

because the put option and $D(T)$ become worthless. Finally, if the asset does not default prior to expiry and the option finishes in the money (or $S_{T} \leqslant K$ equivalently), then the value of the portfolio at the time of expiry is given by

$$
\Pi=K-S_{T}+B e^{r T}>0 .
$$

Proposition 2 The lower bound of a European call option written on a defaultable asset is

$$
C(K, T) \geq S_{0} e^{-d T}-e^{-r T}(1-P D) \cdot K .
$$

Proof. Using equation (4) and the put-call parity relationship:

$$
\begin{aligned}
C(K, T) & =S_{0} e^{-d T}-K \cdot e^{-r T}+P(K, T) \\
& \geq S_{0} e^{-d T}-K \cdot e^{-r T}+e^{-r T} \cdot K \cdot P D \\
& \geq S_{0} e^{-d T}-e^{-r T}(1-P D) \cdot K .
\end{aligned}
$$

\subsection{Lower bounds with positive equity recovery}

We now assume that if a company's stock price falls below a default barrier, $d b$, then the company defaults. Moreover, when a firm defaults, the stock price is worth $R \geq 0$, hereafter referred to as equity recovery.

\subsubsection{Random equity recovery}

We assume that equity recovery at expiry $T$ is a continuously distributed random variable with a probability density function $f_{R}(\rho)$ at a known recovery value $\rho$. Then, we observe that the price of a put option can be written as follows:

$$
\begin{aligned}
P(K, T)= & e^{-r T} E\left[\left(K-S_{T}\right)_{+}\right]= \\
& e^{-r T} E\left[\left(K-S_{T}\right)_{+} \mid D\right] \cdot P D+ \\
& e^{-r T} E\left[\left(K-S_{T}\right)_{+} \mid N D\right] \cdot(1-P D)
\end{aligned}
$$

where $E\left[\left(K-S_{T}\right)_{+} \mid D\right]$ is the conditional expectation if default occurs, $E\left[\left(K-S_{T}\right)_{+} \mid N D\right]$ is the conditional expectation if default does not occur, and $P D=P\left(S_{T} \leq d b\right)$. Let $E(R), \min (R)$, and $\max (R)$ be the expected value, minimum, and maximum values of the recovery at time $T$, respectively. Then, the value of a put option is 


$$
\begin{aligned}
P(K, T) & =e^{-r T} E\left[\left(K-S_{T}\right)_{+} \mid D\right]=0 \text { if } K \leq \min (R) \\
P(K, T) & =e^{-r T} E\left[\left(K-S_{T}\right)_{+} \mid D\right] \cdot P D \\
& =e^{-r T}\left(\int_{\min (R)}^{K}(K-\rho) \cdot f_{R}(\rho) d \rho\right) \cdot P D \text { if } \min (R) \leq K \leq \max (R) \\
P(K, T) & =e^{-r T} E\left[\left(K-S_{T}\right)_{+} \mid D\right]=e^{-r T}(K-E(R)) \cdot P D \text { if } \max (R) \leq K \leq d b .
\end{aligned}
$$

The value of a call option follows from the put-call parity as

$$
\begin{aligned}
C(K, T) & =S_{0} e^{-d T}-K e^{-r T} \text { if } K \leq \min (R), \\
C(K, T) & =e^{-r T}\left(\int_{\min (R)}^{K}(K-\rho) \cdot f_{R}(\rho) d \rho\right) \cdot P D+S_{0} e^{-d T}-K \cdot e^{-r T} \\
\text { if } \min (R) & \leq K \leq \max (R), \\
C(K, T) & =e^{-r T}(K-E(R)) \cdot P D+S_{0} e^{-d T}-K \cdot e^{-r T} \text { if } \max (R) \leq K \leq d b .
\end{aligned}
$$

Hence, for $\max (R) \leq K \leq d b$, the values of the options are

$$
\begin{aligned}
P(K, T) & =\max (K-E(R), 0) e^{-r T} \cdot P D \\
C(K, T) & =S_{0} e^{-d T}-K \cdot e^{-r T}+\max (K-E(R), 0) e^{-r T} \cdot P D .
\end{aligned}
$$

Moreover, since option prices are convex functions of $K$, the lower bounds of calls and puts with $K \geq \max (R)$ are

$$
\begin{aligned}
& P(K, T) \geq \max (K-E(R), 0) e^{-r T} \cdot P D \\
& C(K, T) \geq S_{0} e^{-d T}-K \cdot e^{-r T}+\max (K-E(R), 0) e^{-r T} \cdot P D .
\end{aligned}
$$

Note that both calls and puts equal the lower bounds of Merton for $K \leq$ $\min (R)$. Therefore, the lower bounds of the options in the presence of nonzero recovery is significantly lower than the lower bounds of options with zero recovery that have the same probability of default. Moreover, in the presence of recovery, the options equal their lower bounds for strikes $K \geq \max (R)$, and these values are significantly lower than the lower bounds of the options with zero recovery.

\subsubsection{Constant equity recovery}

Note that if one deals only with options for which $\max (R) \leq K \leq d b$, option prices are given by

$$
\begin{aligned}
P(K, T) & =\max (K-E(R), 0) e^{-r T} \cdot P D \\
C(K, T) & =S_{0} e^{-d T}-K \cdot e^{-r T}+\max (K-E(R), 0) e^{-r T} \cdot P D .
\end{aligned}
$$


As a consequence of convexity, for options with $K \geq \max (R)$, the lower bounds of calls and puts are given by

$$
\begin{aligned}
& P(K, T) \geq \max (K-E(R), 0) e^{-r T} \cdot P D \\
& C(K, T) \geq S_{0} e^{-d T}-K \cdot e^{-r T}+\max (K-E(R), 0) e^{-r T} \cdot P D .
\end{aligned}
$$

The above equations indicate that if one deals with options for which $K \geq$ $\max (R)$, then it is reasonable to replace $E(R)$ by a constant parameter $R$ when examining lower bounds of European calls and puts. Furthermore, if $\min (R)$ and $\max (R)$ are close to each other, then a constant recovery assumption at expiry is also reasonable. Therefore, the lower option bounds for a constant $R$ are given by

$$
\begin{aligned}
& P(K, T) \geq \max (K-R, 0) e^{-r T} \cdot P D \\
& C(K, T) \geq \max \left(S_{0} e^{-d T}-K \cdot e^{-r T}+\max (K-R, 0) e^{-r T} \cdot P D, 0\right)
\end{aligned}
$$

Although in our subsequent analysis we will frequently use (13) and (14), our conclusions can be easily generalized for non-constant recovery.

\subsubsection{Comparison of lower bounds}

Figure 1 (left panel) shows an example of what the proposed call price lower bounds look like compared with Merton's lower bound,

$$
C(K, T) \geq \max \left(S e^{-d T}-K e^{-r T}, 0\right) .
$$

If we assume that the recovery is zero, then a positive $P D$ simply makes the sloped portion of the bound steeper. But if we assume a positive recovery and $P D$, then the bound coincides with Merton's bound up to the expected recovery $R$ and starts decreasing linearly from $R$ at the same slope as the bound with positive $P D$ and zero recovery.

Figure 1 (right panel) shows what can happen if the recovery is indeed positive, but we apply the lower bound with zero recovery. In this case, we will find that some of the observed call prices violate the lower bound. This is an indication that the zero recovery assumption does not hold for the underlying stock.

\section{$<$ Figure 1. Lower Bound for Call Prices $>$}

Figure 2 (left panel) shows an example of what the proposed put price lower bounds look like compared with Merton's lower bound,

$$
P(K, T) \geq \max \left(K e^{-r T}-S e^{-d T}, 0\right) .
$$

Figure 2 (right panel) shows how we can identify the presence of positive recovery by looking at the observed put prices with respect to the lower bound with positive $P D$ and zero recovery. If the recovery is positive, then some of the observed put prices will violate the lower bound with positive $P D$ and zero recovery. 


\section{$<$ Figure 2. Lower Bound for Put Prices $>$}

\section{Data}

We obtain data on options on eight stocks from IVolatility. ${ }^{2}$ The data include daily end-of-day option settlement prices, dividend rates, and interest rates. IVolatility uses LIBOR rates for terms up to one year and ISDA(R) interest rate swaps par mid-rates for longer terms. Our sample includes options on

- General Motors on 15 April 2009,

- MGM Resorts International in 2009,

- Six US financial institutions considered in Taylor et al. (2014) between 2008 and 2009: American International Group (AIG), Bank of America, Bear Stearns, JP Morgan, Lehman Brothers, and Merrill Lynch.

\section{Detecting Positive Equity Recovery with Lower- Bound Violations}

An important implication of (4) and (5) is that these static arbitrage lower bounds are based on minimal assumptions. If one observes a violation of these bounds (referred to hereafter as a lower-bound violation), then the non-zero recovery assumption can be readily rejected.

\subsection{Illustrative example: General Motors}

General Motors (GM) filed for bankruptcy on June 1, 2009, and the "old" GM stock started trading over-the-counter (pink sheets) on June 2. Its stock traded at 75 cents the day before the bankruptcy filing, but shot up to about $\$ 1.20$ a share by June 12, less than two weeks after the bankruptcy filing. By April 15, 2009, the bankruptcy of GM was highly anticipated, and the price of GM stock had plunged to $\$ 1.89$ from around $\$ 40$ in 2007 . With this background in mind, we look at the prices of options on GM stock on April 15, 2009.

The bid and ask prices of call options are shown in Figure 3 (left panel), together with Merton's lower bound and our new proposed lower bound with $P D=40$ per cent and $R=0$. A conservative estimate of the $P D$ of 40 per cent (adjusted to the option maturity of 0.431 years) was implied from one-year credit default swaps.

We observe that the observed prices satisfy Merton's lower bound, but the prices of some of the lowest strike call options violate our proposed lower bound. The violations imply that investors could have made arbitrage profits if $P D$

\footnotetext{
${ }^{2}$ See http://www.ivolatility.com.
} 
was sufficiently high, which was certainly the case in our example. How can we explain the presence of these arbitrage opportunities?

One assumption we made in the lower bound plotted in Figure 3 (left panel) is that the expected equity recovery is zero. We now relax this assumption and suppose that the expected recovery is $\$ 1$. The assumption seems reasonable, since the price of GM stock went from 75 cents to $\$ 1.20$ in the two weeks following the bankruptcy. We plot the lower bound with $P D=40$ per cent and $R=\$ 1$ in Figure 3 (right panel). Since the lower bound under the assumption of positive expected recovery, $R$, coincides with Merton's lower bound when the strike is between zero and $R$, none of the observed call prices violate this new lower bound. Therefore, there were no arbitrage opportunities arising from lower-bound violations if investors believed that when GM eventually defaults, the price of its stock would have dropped to $\$ 1$ or higher, but not to zero.

\section{$<$ Figure 3. Lower-Bound Violations: General Motors >}

This example shows that if the probability of default is positive and we find low strike options violating the lower bound with positive $P D$, but zero $R$, then this can be an indication that the expected equity recovery at default is greater than zero.

\subsection{US financial institutions during the 2007-09 financial crisis}

We apply our proposed methodology to identify stocks that are expected to have a positive equity recovery at default. We select six large financial institutions in the United States during the crisis for several reasons. These institutions were under tremendous stress during the financial crisis. As a result, Lehman Brothers declared bankruptcy, while Bear Stearns and Merrill Lynch were acquired by JP Morgan Chase and Bank of America, respectively. AIG was bailed out by the government. The circumstances leading up to the failure of these firms provide an interesting case study because distressed acquisitions and government bailouts are forms of near-default that often leave equity holders of the firm in distress with small but positive residual value. Moreover, the same set of firms and time period were used in a related study by Taylor et al. (2014) to demonstrate their methodology for extracting the probability of bankruptcy from stock and option prices.

The first step in identifying lower-bound violations is to obtain an estimate of the $P D$. We estimate $P D$ s using the methodology in Carr and $\mathrm{Wu}(2011)$ described in Appendix. One assumption behind the Carr and Wu (2011) methodology is that the equity recovery is zero. As a result, for stocks with positive equity recovery, the methodology results in underestimating $P D$. Therefore, a Carr and $\mathrm{Wu}$ (2011) $P D$ provides a downward-biased estimate of the actual $P D$, which is sufficient for our purpose of detecting lower-bound violations. 
We then plug the Carr-Wu $P D$ s into Orosi's call price lower bound, $C(K, T) \geq$ $\max \left(S_{0} e^{-d T}-e^{-r T}(1-P D) \cdot K, 0\right)$, to determine whether a call price violates this lower bound. We report the frequency of lower-bound violations in Table 1. Note that the price of an American call is greater than or equal to the price of the corresponding European call. Hence, if the above procedure yields an arbitrage violation for an American call, it also implies an arbitrage violation for the corresponding European call. For the same reason, we use ask quotes rather than bid quotes.

\section{$<$ Table 1. Lower-Bound Violations: US Financial Institutions >}

The results show that lower-bound violations occur frequently, indicating rejection of the zero recovery assumption for these firms. The frequency of lowerbound violations is around 80 per cent for three stocks (AIG, JP Morgan, and Lehman Brothers). Even for the stock with the smallest number of violations, the frequency of violations is 27 per cent. The high frequency of lower-bound violations indicates that the expected equity recovery of these stocks during the crisis is often likely to have been positive. In fact, for Bear Stearns, a positive expected recovery is consistent with the fact that the firm was eventually sold to JP Morgan Chase for $\$ 10$ per share when it failed.

All our examples in this section involve government intervention due to the systemic importance of the affected institutions. The government's involvement distorted the processes and outcomes, stripping bondholders of their priority in liquidation in some cases. Although such an event is rare, its effect on equity prices following a bankruptcy is likely to be similar to the result of reorganization, where bondholders make concessions voluntarily.

\section{Extracting Probability of Default from Option Prices When Equity Recovery Is Positive}

Assuming zero recovery when the expected recovery is positive can lead to mispricing of options and misestimation of the probability of default from equity options. There are several ways of estimating the probability of default from options, namely, Carr and Wu (2011), Taylor et al. (2014), and Orosi (2015a). In this section, we focus on the method proposed in Orosi (2015a). Since the formula in Orosi (2015a) does not allow for positive recovery, we first derive an extension of the formula in Orosi (2015a) for the case of positive recovery. Using (11) and the results of Orosi (2015a), an analytic expression for European call options can be derived as:

$$
C(K, T)= \begin{cases}S_{0} e^{-d T}-K e^{-r T} & \text { if } K \leq R \\ S_{0} e^{-d T}-K e^{-r T}+e^{-r T}(K-R) \cdot P D & \text { if } R \leq K \leq d b \\ \left(S_{0} e^{-d T}-e^{-r T} \cdot R \cdot P D\right) \cdot c & \text { if } d b<K\end{cases}
$$


where

$$
\begin{aligned}
c & =\frac{-B_{2}+\sqrt{\left(B_{2}\right)^{2}-4 A_{2} C_{2}}}{2 A_{2}} \\
A_{2} & =1-G(1-P D), \\
B_{2} & =x(1-P D)-1+2 G \cdot D B(1-P D), \\
C_{2} & =-G \cdot D B^{2}(1-P D), \\
D B & =S_{0} e^{-d T}-e^{-r T} \cdot R \cdot P D-e^{-r T}(1-P D) \cdot d b, \\
x & =\frac{e^{-r T} \cdot K}{S_{0} e^{-d T}-e^{-r T} \cdot R \cdot P D} .
\end{aligned}
$$

To derive (17), we extend the methodology in Orosi (2015a) by allowing non-zero equity recovery at default. We start by observing that equation (11) gives the following equations for call option prices when $K \leq d b$ :

$$
C(K, T)= \begin{cases}S_{0} e^{-d T}-K e^{-r T} & \text { if } K \leq R \\ S_{0} e^{-d T}-K e^{-r T}+e^{-r T}(K-R) \cdot P D & \text { if } R \leq K \leq d b .\end{cases}
$$

To obtain analytic call option prices for $K>d b$, apply the following transformations to the strikes and call option prices:

$$
\begin{aligned}
c & =\frac{C(K, T)}{S_{0} e^{-d T}-e^{-r T} \cdot R \cdot P D,} \\
x & =\frac{K e^{-r T}}{S_{0} e^{-d T}-e^{-r T} \cdot R \cdot P D .} .
\end{aligned}
$$

Note that if $R \leq K \leq d b$, the relation between $c$ and $x$ is given by

$$
c=1-(1-P D) \cdot x
$$

or equivalently

$$
x=\frac{1-c}{1-P D}
$$

To ensure that the transformed call option prices, $c$, are decreasing and convex functions of $x$ when $K>d b$, we use the following expression to model the dependence between these two variables

$$
x=\frac{1-c}{1-P D}+G \frac{(1-c)^{2}}{c},
$$

where $G$ is a positive constant. Note that the above relation also guarantees the continuity of call prices at $K=d b$ and $c \rightarrow 0$ as $x \rightarrow 0$.

Equation (18) can be rearranged as follows:

$$
c^{2}(1-G(1-P D))+c(x(1-P D)-1+2 G(1-P D))-G(1-P D)=0 .
$$

Finally, equation (17) is obtained as the positive root of the above quadratic equation. 


\subsection{Illustrative example: MGM Resorts International}

We calibrate the call option formula in (17) to call options on MGM stock in 2009. We chose MGM because we have access to data on the credit default swaps and also because MGM did not pay any dividends after 2000. This simplifies our analysis, since American-style call options have no early exercise premia when the dividend is zero, and thus can be treated as European options.

We fit two versions of the formula. In Model $1, R, P D$, and $d b$ are parameters that are extracted from option prices, whereas Model 2 assumes that $R$ is zero. For each trading day in the sample, (17) is calibrated by minimizing the root mean squared per cent pricing errors:

$$
\sqrt{\frac{1}{n} \sum_{i=1}^{n}\left(\frac{C_{i j}\left(\theta_{j}\right)-C_{i j}}{C_{i j}}\right)^{2}},
$$

where $\theta_{j}$ represents the parameters for the $j^{\text {th }}$ given trading day, the $\left\{C_{i j}\right\}_{i=1}^{n}$ are the observed option prices on the $j^{\text {th }}$ trading day (for all strikes and expiries), and the $C_{i j}\left(\theta_{j}\right)$-s are the option prices based on the model.

We fit the model to in-the-money call options because Orosi (2015b) points out that the model provides a poor fit for out-of-the-money calls. On many days, we cannot find enough in-the-money call options to calibrate the parameters, so we use simulated prices instead. First, for each trading day in the sample, a cubic Hermite spline-based interpolant is fitted to all available call options with the second-longest maturity. The average maturity of the options used is around 0.74 years, which is approximately 9 months. Then, using this interpolant, 15 uniformly distributed call option prices with the same maturity are generated so that the minimum of the generated strike prices corresponds to 70 per cent of the minimum values of all available strike prices, and the maximum of the generated strike prices corresponds to the stock price.

\section{$<$ Table 2. Probability of Default and Equity Recovery Rate: MGM Resorts International (2009) >}

The results of the model calibration are reported in Table 2, and the five-day moving averages of the estimated $P D$ s are plotted in Figure 4 . We also plot the $P D$ s computed from American put option prices using the methodology in Car and $\mathrm{Wu}$ (2011) for comparison. Moreover, to assess whether the equity implied probabilities agree with those extracted from credit markets, we use CDS with a maturity of five years. We first estimate the constant hazard rate, $\lambda_{C D S}$, from CDS spreads by using the relation:

$$
\lambda_{C D S}=\frac{S P}{1-R_{\text {Bond }}},
$$

where $S P$ is the CDS spread and $R_{B o n d}$ is the bond recovery rate that is assumed to be 40 per cent. 
To make the $P D$ s implied from options and those implied from CDS comparable in terms of their time horizon, we use the relation in equation (21) to calculate one-year $P D$ s by adjusting $P D$ s estimated from options of different maturities and $\lambda_{C D S}$ estimated from five-year CDS spreads.

We report the average estimates of the model parameters for both Model 1 and Model 2 in Table 2. The times-series plot of the $P D$ s computed from Model 1 and Model 2 show that Model 2 significantly underestimates $P D$ s (Figure 4A). The $P D$ s from Model 1 are comparable with the $P D$ s implied from American puts or CDS. However, the $P D$ s from Model 2 are significantly lower than the $P D$ s implied from American puts or CDS.

We also plot the estimated equity recovery and default barrier in Figure 4B. The average estimated equity recovery and default barrier for MGM in 2009 are $\$ 1.37$ and $\$ 2.78$, respectively. The two quantities are highly correlated, with a correlation of 0.69 . The equity recovery is mildly correlated with the probability of default, with a correlation of 0.19 , whereas the default barrier is negatively correlated with the probability of default, with a correlation of -0.28 . It is unclear a priori how the expected equity recovery and default barrier should be related to the probability of default. Moreover, estimating the precise level of the equity recovery and default barrier is a much harder task than estimating the probability of default. Therefore, we do not go into a detailed discussion of the relation among these three variables in this paper.

\section{$<$ Figure 4. Probability of Default, Equity Recovery, and Default Barrier: MGM >}

Our example illustrates that ignoring a positive expected equity recovery at default has important implications for estimating probability of default from observed option prices. Therefore, other methods of estimating probability of default from option prices such as Carr and Wu (2011) and Taylor et al. (2014) must be used with caution when the equity recovery is expected to be positive.

\section{Conclusion}

In the presence of positive expected equity recovery, the standard methods that assume zero equity recovery at default misestimate the probability of default implicit in option prices. We introduce a simple method to detect stocks with positive expected equity recovery by examining option prices and propose a method to extract the probability of default from option prices in the presence of positive expected equity recovery. Our methodology is based on new lower bounds for European call and put option prices when the expected default probability and equity recovery are known. Our empirical results show that assuming zero recovery leads to significant mispricing of options and misestimation of implied probability of default.

Our methodology is particularly useful in examining firms that are close to filing or going through Chapter 11 bankruptcy, but with a high probability of successful reorganization. For these firms, it is important to take positive 
expected equity recovery into account when pricing options. Systemically important firms such as large financial institutions, automobile companies, and airlines are special cases in which the possibility of government bailout plays an important role in inducing a positive expected equity recovery. We leave an in-depth study of firms in Chapter 11 bankruptcy using our methodology for future research.

\section{Appendix. Probability of Default Implied from Puts: Carr and Wu (2011)}

Carr and Wu (2011) define a unit recovery claim (URC) as a contract that pays one dollar at default whenever the company defaults prior to the option expiry and pays zero otherwise. Under the assumption of a constant default arrival rate, $\lambda$, the value of a URC is given by

$$
U(T)=\int_{0}^{T} \lambda e^{-r s} e^{-\lambda s} d s=\lambda \frac{1-e^{-(r+\lambda) T}}{r+\lambda} .
$$

The probability of default, $P D$, can be computed from the default arrival rate, $\lambda$, using the relation,

$$
P D=1-e^{-\lambda T} .
$$

Carr and $\mathrm{Wu}$ (2011) show that for low strike prices, the URC can be replicated by an American put, $P_{A m}(K, T)$, the following way:

$$
U(T)=\frac{P_{A m}(K, T)}{K} .
$$

$P D$ can be easily calculated by first calculating the value of $U(T)$ using (22),

then determining the value of $\lambda$ from (20), and finally plugging $\lambda$ into the equation (21).

To compute $U(T)$, Carr and $\mathrm{Wu}$ (2011) use only options that satisfy the following criteria: (i) the bid price is greater than zero; (ii) the time-to-maturity is greater than 360 days; (iii) the strike price is $\$ 5$ or less; and (iv) the absolute value of the put's delta is not larger than 0.15 .

\section{References}

[1] Bayraktar, E., \& Yang, B. (2011). A unified framework for pricing credit and equity derivatives. Mathematical Finance, 21 (3), 493-517.

[2] Breeden, D., \& Litzenberger, R. (1978). Price of state-contingent claims implicit in options prices. Journal of Business, 51 (4), 621-651. 
[3] Broadie, M., Chernov, M., \& Sundaresan, S. (2007). Optimal debt and equity values in the presence of Chapter 7 and Chapter 11. Journal of Finance, 62 (3), 1341-1377.

[4] Carr, P., \& Linetsky, V. (2006). A jump to default extended CEV model: an application of Bessel processes. Finance and Stochastics, 10 (3), 303-330.

[5] Carr, P., \& Madan, D. (2010). Local volatility enhanced by a jump to default. SIAM Journal of Financial Mathematics, 1 (1), 2-15.

[6] Carr, P., \& Wu, L. (2009). Stock options and credit default swaps: a joint framework for valuation and estimation. Journal of Financial Econometrics, 8 (1), 1-41.

[7] Carr, P., \& Wu, L. (2011). A simple robust link between American puts and credit protection. Review of Financial Studies, 24 (2), 473-505.

[8] Davydenko, S. A., (2012). When do firms default? A study of the default boundary. Working paper, University of Toronto.

[9] De Marco, S., Hillairet, C., \& Jacquier, A. (2013). Shapes of implied volatility with positive mass at zero. Working paper, Ecole Polytechnique, Paris.

[10] Fan, H., \& Sundaresan, S. (2000). Debt valuation, renegotiation, and optimal dividend policy. Review of Financial Studies, 13 (4), 1057-1099.

[11] Hackbarth, D., Hennessy, C. A., \& Leland, H. E. (2007). Can the trade-off theory explain debt structure?. Review of Financial Studies, 20 (3), 13891428.

[12] Leland, H. E. (1994). Corporate debt value, bond covenants, and optimal capital structure. Journal of Finance, 49 (4), 1213-1252.

[13] Leland, H. E., \& Toft, K. B. (1996). Optimal capital structure, endogenous bankruptcy, and the term structure of credit spreads. Journal of Finance, $51(3), 987-1019$.

[14] Linetsky, V. (2006). Pricing equity derivatives subject to bankruptcy. Mathematical Finance, 16 (2), 255-282.

[15] Merton, R. C. (1973). Theory of rational option pricing. Bell Journal of Economics and Management Science, 4 (1), 141-183.

[16] Merton, R. C. (1974). On the pricing of corporate debt: the risk structure of interest rates. Journal of Finance, 29 (2), 449-470.

[17] Orosi, G. (2014). Novel no-arbitrage conditions for options written on defaultable assets. Journal of Derivatives \& 3 Hedge Funds, 20 (4), 201-205.

[18] Orosi, G. (2015a). Closed-form interpolation-based formulas for European call options written on defaultable assets. Journal of Asset Management,16 (4), 236-242. 
[19] Orosi, G. (2015b). Estimating option-implied risk-neutral densities: a novel parametric approach. Journal of Derivatives, 23 (1), 41-61.

[20] Taylor, S. J., Tzeng, C., \& Widdicks, M. (2014). Bankruptcy probabilities inferred from option prices. Journal of Derivatives, 22 (2), 8-31. 
< Table 1. Lower-Bound Violations: US Financial Institutions >

\begin{tabular}{|l|c|c|c|}
\hline & $\begin{array}{c}\text { Violations } \\
(\%)\end{array}$ & $\begin{array}{c}\text { Carr-Wu Prob. of Default } \\
\text { mean (std) }\end{array}$ & $\begin{array}{c}\text { \# Options } \\
\text { filtered }\end{array}$ \\
\hline AIG & 80 & $0.12(0.14)$ & 186 \\
Bear Sterns & 27 & $0.17(0.17)$ & 51 \\
Bank of America & 64 & $0.12(0.14)$ & 347 \\
JP Morgan & 81 & $0.08(0.14)$ & 354 \\
Lehman Brothers & 81 & $0.08(0.08)$ & 123 \\
Merrill Lynch & 53 & $0.12(0.14)$ & 73 \\
\hline
\end{tabular}

Note: We report the frequency of violation of Orosi's lower bound for call options, $C(K, T) \geq \max \left(S_{0} e^{-d T}-e^{-r T}(1-P D) \cdot K, 0\right)$, using all call options on the six US stocks between 2008 and 2009. To do this, we first compute Carr and $\mathrm{Wu}$ (2011) probabilities of default, $P D$, by using the methodology described in Appendix. We then plug the estimated $P D$ s into the lower-bound formula to determine whether an option price violates it. We also report the number of options used in estimating Carr-Wu $P D$ s. The filtered options satisfy the following conditions: (i) the bid price is greater than zero; (ii) the time-to-maturity is greater than 360 days; (iii) the strike price is $\$ 5$ or less; and (iv) the absolute value of the put's delta is not larger than 0.15 . 
< Table 2. Probability of Default and Equity Recovery Rate: MGM Resorts International (2009) >

\begin{tabular}{|l|c|c|c|c|c|}
\hline & $\begin{array}{c}\text { Root Mean } \\
\text { Squared (\%Error) }\end{array}$ & $G$ & $R(\%)$ & $P D(\%)$ & $d b(\%)$ \\
\hline Model 1: R>0 & & & & & \\
Mean & 0.83 & 0.3869 & 19.11 & 23.13 & 35.90 \\
Standard Deviation & $\mathrm{n} / \mathrm{a}$ & 0.3037 & 17.43 & 21.93 & 12.41 \\
\hline Model 2: R=0 & & & & & \\
Mean & 2.23 & 0.61 & 0 & 4.52 & 26.66 \\
Standard Deviation & n/a & 0.81 & $\mathrm{n} / \mathrm{a}$ & 7.53 & 21.32 \\
\hline
\end{tabular}

Note: We calibrate the call option price formula in (17) to call options on MGM Resorts International stock in 2009. Model 1 assumes positive equity recovery and thus estimates $\mathrm{R}$ by fitting the observed call prices to the pricing formula. Model 2 assumes zero recovery and thus $\mathrm{R}$ is simply fixed at zero. For each trading day in the sample, the model is calibrated by minimizing the root mean squared per cent pricing errors of generated in-the-money options. To generate in-the-money call option prices, a cubic Hermite spline-based interpolant is fitted to all available call options with the second-longest maturity. Then, using this interpolant, 15 uniformly distributed call option prices with the same maturity are generated so that the minimum of the generated strike prices corresponds to 70 per cent of the minimum values of all available strike prices, and the maximum of the generated strike prices corresponds to the stock price. 


\section{$<$ Figure 1. Lower Bound for Call Prices $>$}
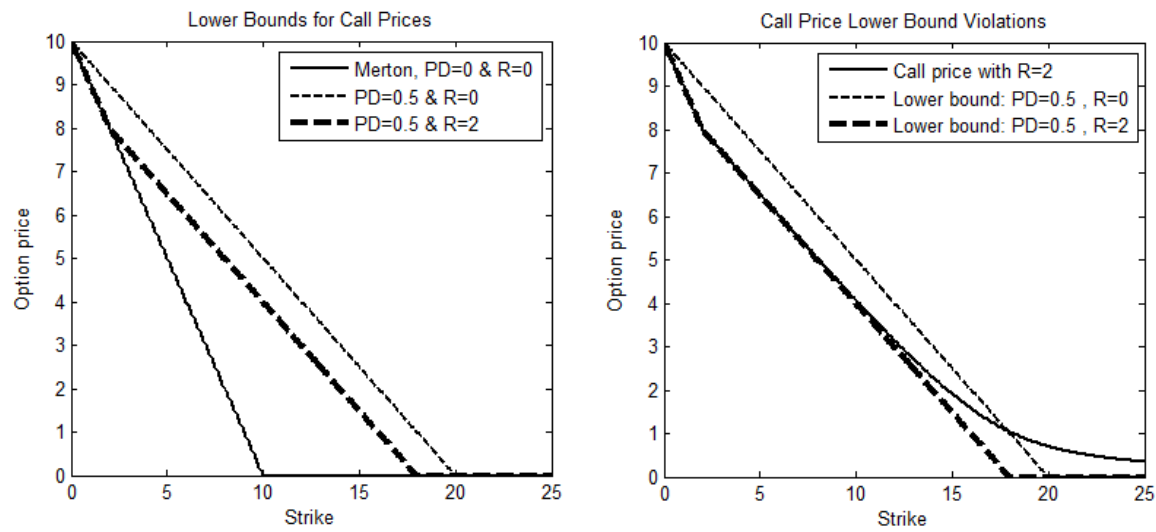

Note: The parameters used are: stock price $(\mathrm{S})=\$ 10$, riskfree rate $(\mathrm{r})=0 \%$, dividend yield $(\mathrm{d})=0 \%$, time-to-maturity $(\mathrm{T})=1$ year, default barrier $(\mathrm{db})=\$ 4$. Merton's lower bound for call prices, $C$, is $C(K) \geq \max \left(S e^{-d T}-K e^{-r T}, 0\right)$, where $K$ is the strike price. The lower bound for call prices with a positive probability of default, $P D$, is $C(K, T) \geq S_{0} e^{-d T}-K$. $e^{-r T}+\max (K-R, 0) e^{-r T} \cdot P D$. The call prices on the right panel are generated using (17) with $G=0.12$.

\section{$<$ Figure 2. Lower Bound for Put Prices $>$}
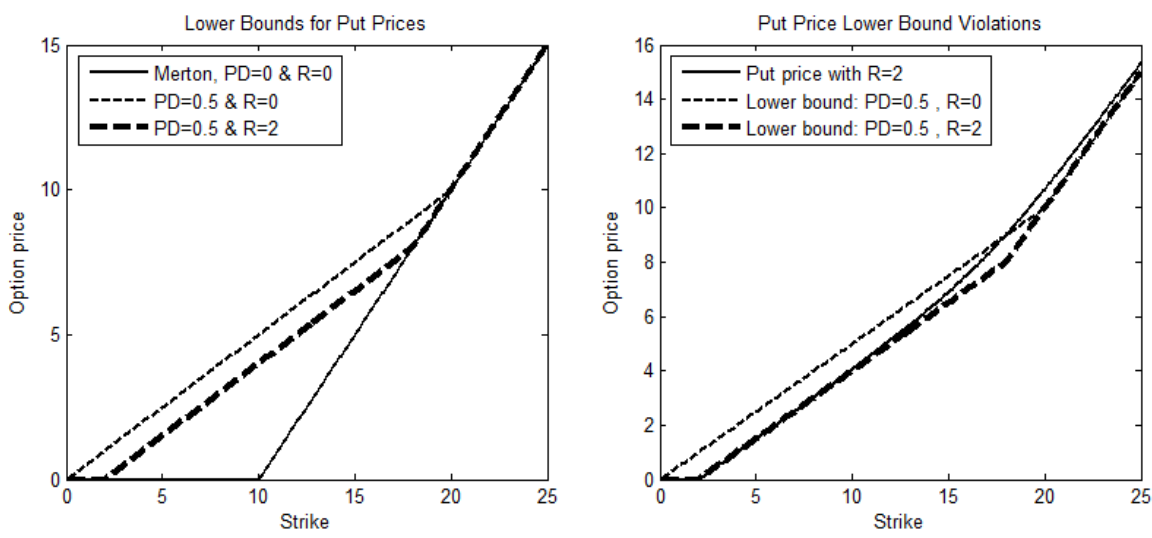

Note: The parameters used are: stock price $(\mathrm{S})=\$ 10$, riskfree rate $(\mathrm{r})=0 \%$, dividend yield $(\mathrm{d})=0 \%$, time-to-maturity $(\mathrm{T})=1$ year, default barrier $(\mathrm{db})=\$ 4$. Merton's lower bound for put prices, $P$, is $P(K) \geq \max \left(K e^{-r T}-S e^{-d T}, 0\right)$, where $K$ is the strike price. The lower bound for put prices with a positive probability of default, $P D$, is $P(K, T) \geq \max (K-R, 0) e^{-r T}$. $P D$. The put prices on the right panel are generated using put-call parity and (17) with $G=0.12$. 
$<$ Figure 3. Lower-Bound Violations: General Motors >

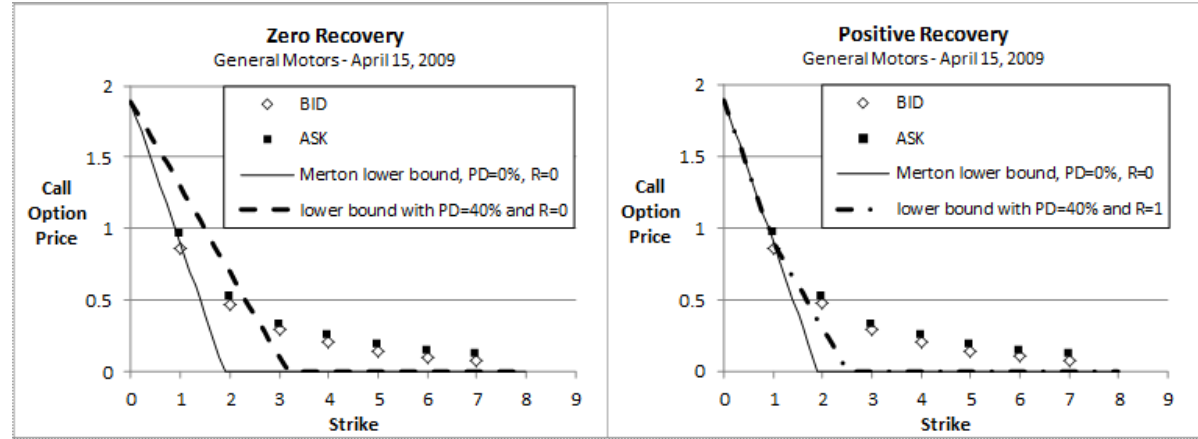

Note: We plot the bid and ask prices of call options on General Motors' stock on April 15, 2009. The parameters used are: stock $\operatorname{price}(\mathrm{S})=\$ 1.89$, riskfree $\operatorname{rate}(\mathrm{r})=0.93 \%$, dividend yield $(\mathrm{d})=0 \%$, timeto-maturity $(\mathrm{T})=0.431$ year, and probability of default $(\mathrm{PD})=40 \%$. The probability of default was estimated from credit default swaps on General Motors. Merton's lower bound for call prices, $C$, is $C(K) \geq \max \left(S e^{-d T}-K e^{-r T}, 0\right)$ where $K$ is the strike price. The lower bound for call prices with a positive probability of default, $P D$, is $C(K, T) \geq S_{0} e^{-d T}-K \cdot e^{-r T}+\max (K-R, 0) e^{-r T} \cdot P D$. 


\section{$<$ Figure 4. Probability of Default, Equity Recovery, and Default Barrier: MGM >}
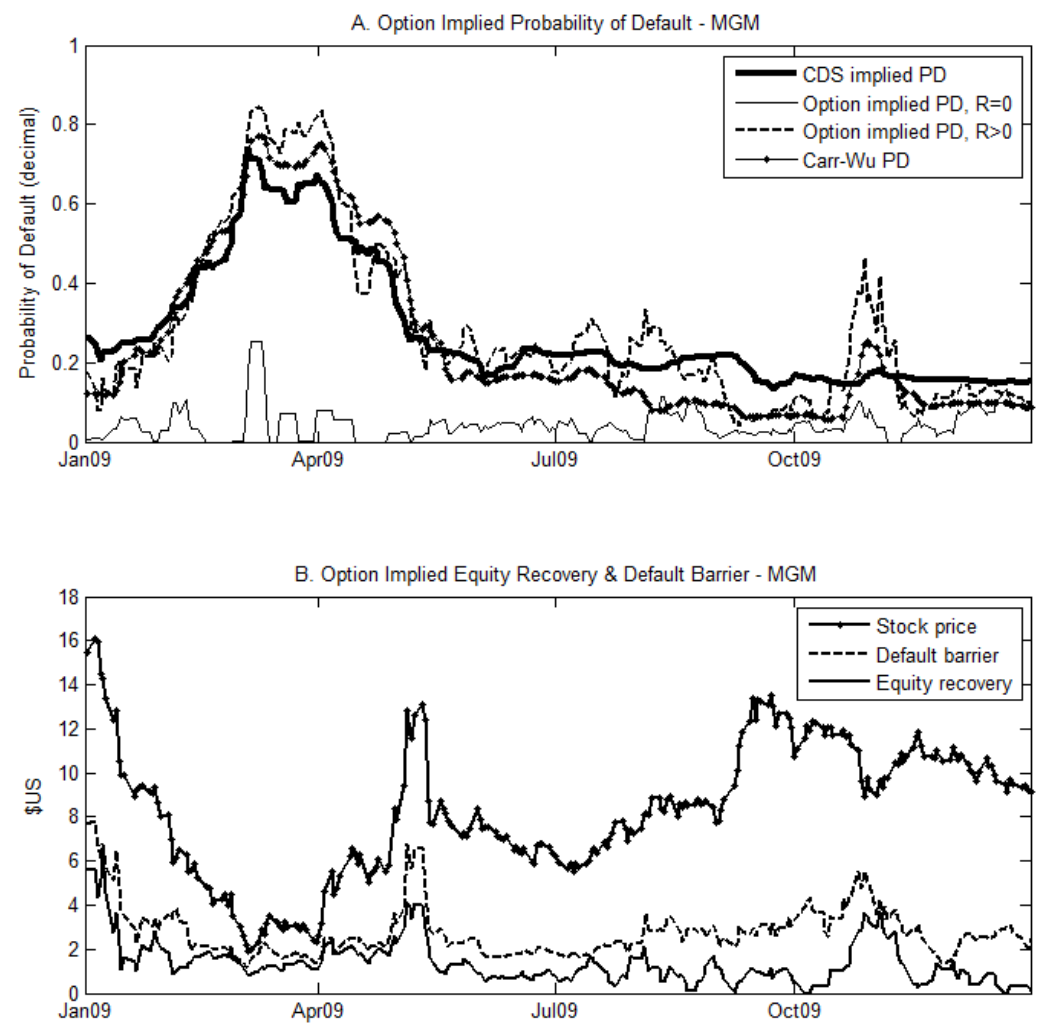

Note: We calibrate the call option price formula in (17) to call options on MGM Resorts International stock in 2009. Model 1 assumes positive equity recovery and thus estimates $\mathrm{R}$ by fitting the observed call prices to the pricing formula. Model 2 assumes zero recovery and thus $\mathrm{R}$ is simply fixed at zero. For each trading day in the sample, the model is calibrated by minimizing the root mean squared per cent pricing errors of generated in-the-money options. To generated in-the-money call option prices, a cubic Hermite spline-based interpolant is fitted to all available call options with the second-longest maturity. Then, using this interpolant, 15 uniformly distributed call option prices with the same maturity are generated so that the minimum of the generated strike prices corresponds to 70 per cent of the minimum values of all available strike prices, and the maximum of the generated strike prices corresponds to the stock price. 